\title{
Effects of 5.4 MeV Alpha-particle Irradiation on the Electrical Properties of Nickel Schottky Diodes on $4 \mathrm{H}-\mathrm{SiC}$
}

\author{
E. Omotoso ${ }^{\text {a, b, }}$, W.E. Meyer ${ }^{\text {a }}$, F.D. Auret ${ }^{\text {a }}$, A.T. Paradzah ${ }^{\text {a }}$, M. Diale ${ }^{\text {a }}$, S.M.M. Coelho ${ }^{\text {a }}$, P.J. Janse van \\ Rensburg $^{\text {a }}$, P.N.M. Ngoepe ${ }^{\mathrm{a}}$ \\ ${ }^{a}$ Department of Physics, University of Pretoria, Private Bag X20, Hatfield 0028, South Africa \\ ${ }^{b}$ Department of Physics, Obafemi Awolowo University, Ile-Ife, 220005, Nigeria
}

\begin{abstract}
Current-voltage, capacitance-voltage and conventional deep level transient spectroscopy at temperature ranges from 40-300 $\mathrm{K}$ have been employed to study the influence of alpha-particle irradiation from an ${ }^{241} \mathrm{Am}$ source on $\mathrm{Ni} / 4 \mathrm{H}-\mathrm{SiC}$ Schottky contacts. The nickel Schottky barrier diodes were resistively evaporated on n-type $4 \mathrm{H}-\mathrm{SiC}$ samples of doping density of $7.1 \times 10^{15} \mathrm{~cm}^{-3}$. It was observed that radiation damage caused an increase in ideality factors of the samples from 1.04 to 1.07 , an increase in Schottky barrier height from 1.25 to $1.31 \mathrm{eV}$, an increase in series resistance from 48 to $270 \Omega$ but a decrease in saturation current density from 55 to $9 \times 10^{-12} \mathrm{Am}^{-2}$ from $I-V$ plots at $300 \mathrm{~K}$. The free carrier concentration of the sample decreased slightly after irradiation. Conventional DLTS showed peaks due to four deep levels for as-grown and five deep levels after irradiation. The Richardson constant, as determined from a modified Richardson plot assuming a Gaussian distribution of barrier heights for the as-grown and irradiated samples were 133 and $151 \mathrm{Acm}^{-2} \mathrm{~K}^{-2}$, respectively. These values are similar to literature values.
\end{abstract}

Keywords: Irradiation, DLTS, SiC, Defects, Schottky, alpha-particles

\section{Introduction}

$\mathrm{SiC}$ is a promising semiconductor with a wide band-gap of $3.26 \mathrm{eV}$ [1]. Because of its wide bandgap, $\mathrm{SiC}$ is a suitable substrate for developing devices that are capable of operating at high temperature as well as in harsh radiation fields $[2,3]$. The electrical and thermal properties of $\mathrm{SiC}$ make it suitable devices in the electronics operating at high power, high temperature and high frequency [4]. Irradiation is used to introduce defects in semiconductors in order to investigate the defects' properties by means of deep-level transient spectroscopy (DLTS) on Schottky diodes. Effects of radiation and temperature on semiconductors are technologically important for radiation to sensing applications as well as manufacturing processes and high temperature and high power applications [5].

It has been reported by many researchers that some wide band-gap semiconductors such as $\mathrm{SiC}$ and $\mathrm{GaN}$ are radiation hard which make them suitable for use in harsh radiation environments [3]. Effects of electron, proton, fast electron and fast neutron irradiation on $\mathrm{SiC}$ have been investigated by different researchers [3, 6-8]. To the best of our knowledge, the effect of alpha-particles irradiation on $\mathrm{Ni} / 4 \mathrm{H}-\mathrm{SiC}$ has not been reported.

In this work, the change in electrical properties of $\mathrm{Ni} / 4 \mathrm{H}-\mathrm{SiC}$ due to alpha-particle irradiation has been investigated by means of current-voltage $(I-V)$, capacitance-voltage $(C-V)$ and DLTS measurements. The major aim was to determine the effect of $5.4 \mathrm{MeV}$ alpha-particles irradiation on the electrical properties and diode performance of n-type $4 \mathrm{H}-\mathrm{SiC}$.

\section{Experimental Procedure}

The Schottky diodes were fabricated on the Si face of chips cut from an $n$-type (nitrogen doped) $4 \mathrm{H}-\mathrm{SiC}$ wafer, double polished with resistivity of $0.02 \Omega-\mathrm{cm}$ and doping density of $7.1 \times 10^{15} \mathrm{~cm}^{-3}$, supplied by CREE Res. Inc. Samples were degreased by boiling for 5 minutes each in trichloroethylene, acetone and methanol, followed by a 1 minute rinse in de-ionized water. They were etched in $40 \%$ hydrogen fluoride for 30 seconds, then rinsed in de-ionized water and followed by blowing dry with nitrogen gas prior to thermal evaporation of the nickel ohmic contact on the back surface of the samples. The ohmic contact with a thickness of $3000 \AA$ was deposited at a rate of $0.4 \AA$ 
$\mathrm{s}^{-1}$. The samples were annealed in a tube furnace under flowing argon gas at $950^{\circ} \mathrm{C}$ for 10 minutes to form nickel silicides [9]. Hereafter, the samples were cleaned in an ultrasonic bath for 3 minutes each in trichloroethylene, acetone and methanol, followed by a 1 minute rinse in de-ionized $\mathrm{H}_{2} \mathrm{O}$. They were also blown dry with nitrogen gas before the fabrication of nickel Schottky diodes. The nickel Schottky contacts were deposited through a metal contact mask and had an area of $2.4 \times 10^{-3} \mathrm{~cm}^{2}$ and a thickness of $1000 \AA$ deposited at a rate of $0.2 \AA^{-1}$ under a vacuum of approximately $1 \times 10^{-5}$ Torr.

The current-voltage $(I-V)$ and capacitance-voltage $(C-V)$ measurements of the sample were carried out at room temperature to test the qualities of the contacts. The $I-V$ and $C-V$ measurements were carried out by HP 4140 B pA meter/DC voltage source and HP 4192A LF Impedance Analyzer, respectively. DLTS was used to characterize the defects present in the sample before and after alphaparticles irradiation.

The sample was irradiated with alpha-particle by placing an ${ }^{241} \mathrm{Am}$ source on top of the Schottky diodes. The irradiation was carried out at room temperature and lasted for 2 hours. The sample received the fluence of $5.1 \times 10^{10}$ alpha-particles- $\mathrm{cm}^{-2}$ from the foil fluence rate of $7.1 \times 10^{6}$ alphaparticles $-\mathrm{cm}^{-2}-\mathrm{s}^{-1}$. The characterization of the sample was repeated.

\section{Results and Discussion}

\subsection{I-V characteristics at room temperature}

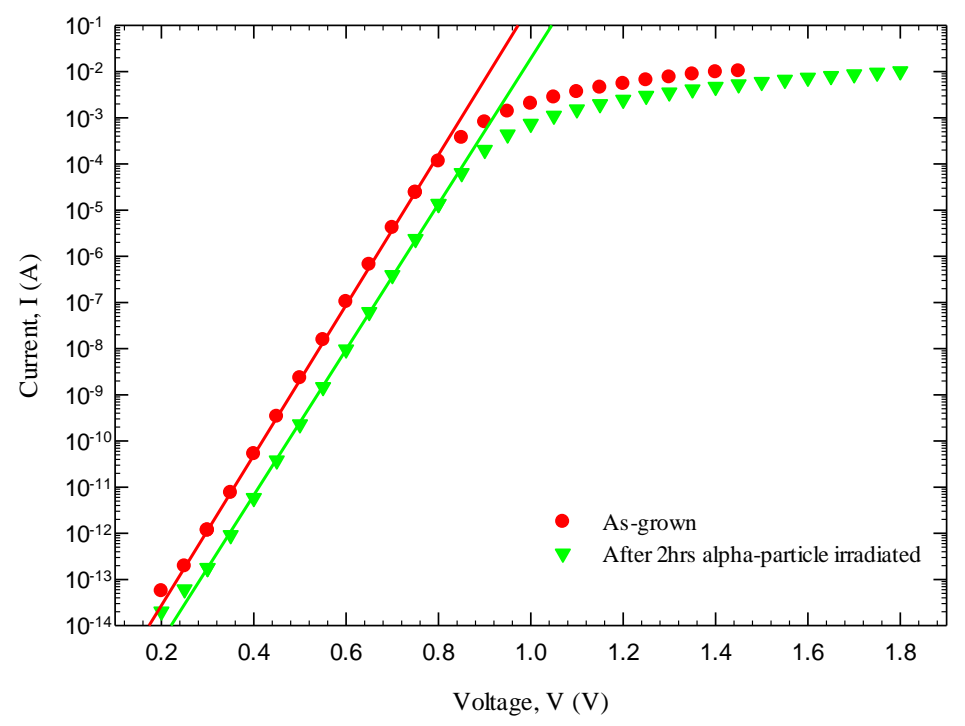

Fig. 1. Forward $I-V$ characteristics of $\mathrm{Ni} / 4 \mathrm{H}-\mathrm{SiC}$ Schottky diodes before and after irradiation measured at $300 \mathrm{~K}$.

Fig. 1 shows the forward semi-logarithmic $I-V$ characteristics of the Schottky barrier diode measured at $300 \mathrm{~K}$ before and after irradiation. The effect of irradiation on the $\mathrm{Ni} / 4 \mathrm{H}-\mathrm{SiC}$ diode can be quantified in terms of the ideality factor $(n)$, Schottky barrier height $(\mathrm{SBH})$, saturation current $\left(I_{s}\right)$ and series resistance $\left(R_{s}\right)$ obtained from the plot. Measurements on the Schottky contacts were taken before and after the samples were irradiated. Table 1 compares the properties of the sample before and after irradiation at $300 \mathrm{~K}$. The SBH of the contacts were determined from the $I$ - $V$ characteristics analysed by using the thermionic emission model $[10,11]$. The $I_{s}$ was derived from the straight line intercept of $\ln I-V$ plot at $V=0$

$$
I_{S}=A A^{*} \exp \left(-\frac{\phi_{I-V}}{k T}\right)
$$

where $A$ is the effective diode area, $A^{*}$ is the effective Richardson constant, $\phi_{I-V}$ is the effective SBH at zero bias, $k$ is the Boltzmann constant and $T$ is absolute temperature in Kelvin.

From the Eq. 1, SBH, $\phi_{I-V}$ is given as: 


$$
\phi_{I-V}=\frac{k T}{q} \ln \left(\frac{A A^{*} T^{2}}{I_{S}}\right)
$$

and $n$ is given as:

$$
n=\frac{q}{k T}\left(\frac{d V}{d(\ln I)}\right)
$$

which is unity for an ideal diode (i.e current flows entirely due to thermionic emission). But, $n$ is always greater than one, which describes the deviation of the experimental $\ln I-V$ data from the ideal thermionic model. From Table $1, n, \phi_{I-V}$ and $R_{s}$ increases with radiation, but $I_{s}$ decreases with radiation.

Table 1

Comparison of some electrical parameters of $\mathrm{Ni} / 4 \mathrm{H}-\mathrm{SiC}$ before and after alpha-particle irradiation estimated from $I-V$ and $C$ $V$ characteristics at $300 \mathrm{~K}$.

\begin{tabular}{lccccccc}
\hline Samples & $\boldsymbol{n}$ & $\boldsymbol{I}_{\boldsymbol{s}}(\mathbf{A})$ & $\boldsymbol{R}_{\boldsymbol{s}}(\boldsymbol{\Omega})$ & $\boldsymbol{V}_{\boldsymbol{b i}}(\mathbf{V})$ & $\boldsymbol{N}_{\boldsymbol{t}}\left(\mathbf{c m}^{-\mathbf{3}}\right)$ & $\boldsymbol{\phi}_{\boldsymbol{I - V}}(\mathbf{e V})$ & $\boldsymbol{\phi}_{C-\boldsymbol{V}}(\mathbf{e V})$ \\
\hline As-grown & 1.04 & $15.5 \times 10^{-18}$ & 48 & 1.07 & $7.8 \times 10^{15}$ & 1.25 & 1.36 \\
Irradiated & 1.07 & $2.6 \times 10^{-18}$ & 270 & 1.23 & $7.4 \times 10^{15}$ & 1.31 & 1.52 \\
\hline
\end{tabular}

\section{2. $C$-V characteristics at room temperature}

Fig. 2 shows the plot of $C^{-2}\left(\mathrm{pF}^{-2}\right)$ as a function of voltage, $V(\mathrm{~V})$ before and after alpha-particle irradiation measured at $1 \mathrm{MHz}$ frequency with the sample at room temperature. The capacitance increased with decreasing reverse voltage for both, but the capacitance after irradiation was lower. This is as a result of defects introduced into the sample during the irradiation process which traps electrons $[12,13]$. The $C-V$ parameters are tabulated in Table 1 . The zero-bias barrier heights for both samples were determined from Eq. 4.

$$
\phi_{C-V}=V_{b i}+\frac{k T}{q} \ln \frac{N_{c}}{N_{d}}
$$

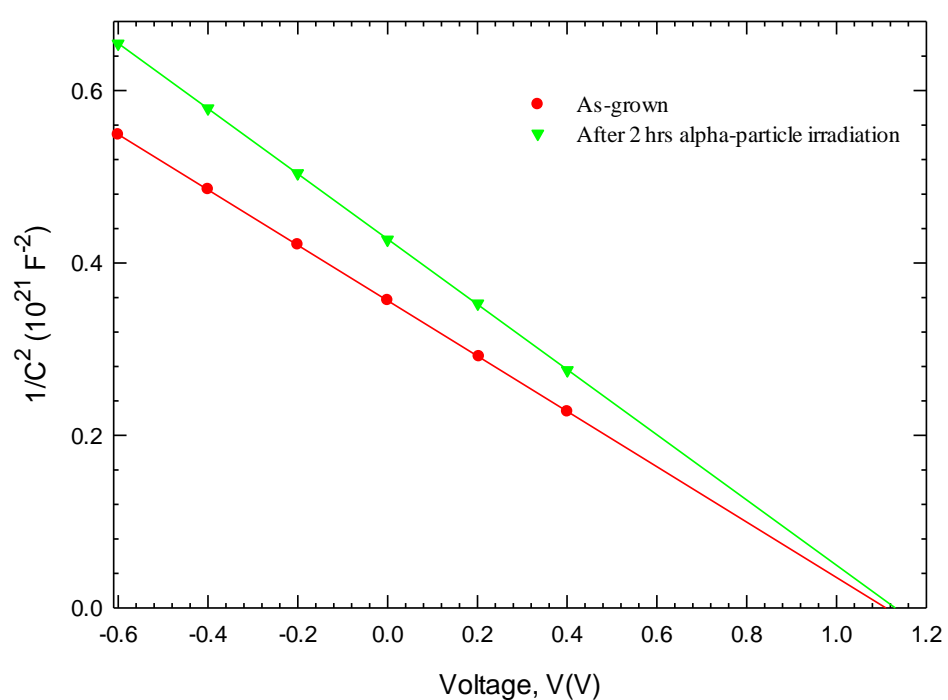

Fig. 2. $1 / \mathrm{C}^{2}$ as a function of voltage characteristics of $\mathrm{Ni} / 4 \mathrm{H}-\mathrm{SiC}$ before and after 5.4 MeV alpha-particles irradiation at $300 \mathrm{~K}$.

From Fig. 2, the free carrier concentration of the sample before and after radiation was determined from the slope of the plots. The free carrier removal rate, $y$ can be obtained from Eq. 5 below:

$$
\eta=\frac{\Delta\left(N_{D}-N_{A}\right)}{\varphi}
$$


where $\Delta\left(N_{D}-N_{A}\right)$ is the change in free carrier concentration before and after irradiation, $\varphi$ is the fluence to which the sample was bombarded [14]. At room temperature $(300 \mathrm{~K})$, a fluence of $5.1 \times$ $10^{10}$ alpha-particles- $\mathrm{cm}^{-2}$ resulted in a change in carrier concentration from $7.8 \times 10^{15}$ to $7.4 \times 10^{15}$ leading to a carrier removal rate of $7.8 \times 10^{3} \mathrm{~cm}^{-1}$.

Comparing the $\mathrm{SBH}$ for $I-V$ and $C$ - $V$ measurements, it was observed experimentally that the SBH's do not agree. The SBH increased after irradiation for both $I-V$ and $C-V$, but greater for $C-V$ measurements. This is in confirmation with what has been reported in literature $[15,16]$. The causes for a difference in this parameters are deep impurity level, surface inhomogeneity, quantum mechanical tunnelling, interfacial layer and states, image force lowering, and edge leakage currents [17].

\subsection{I-V Characteristics at Temperature range 40-300 K}

Fig. 3 shows the semi-logarithmic forward bias $I-V$ characteristics for both as-grown and irradiated $\mathrm{Ni} / 4 \mathrm{H}-\mathrm{SiC}$ Schottky barrier diodes measured from temperature ranges $40-300 \mathrm{~K}$ in other to determine the effect of temperature on the electrical properties of the samples.

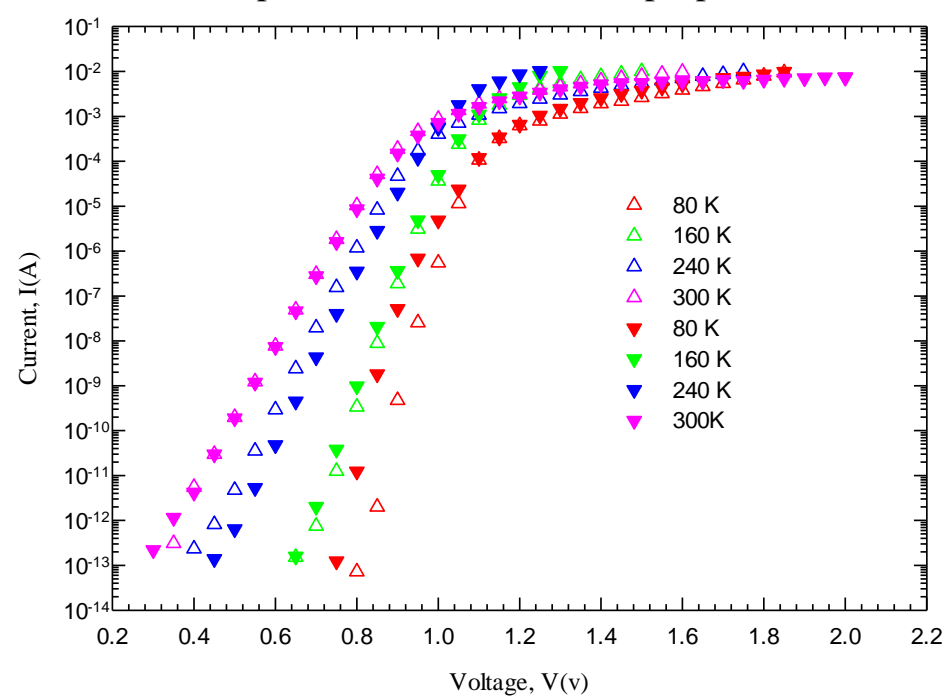

Fig. 3. The current versus voltage characteristics of $\mathrm{Ni} / 4 \mathrm{H}-\mathrm{SiC}$ before and after irradiation measured at temperature range 40-300 K. The solid symbols represent after irradiation.

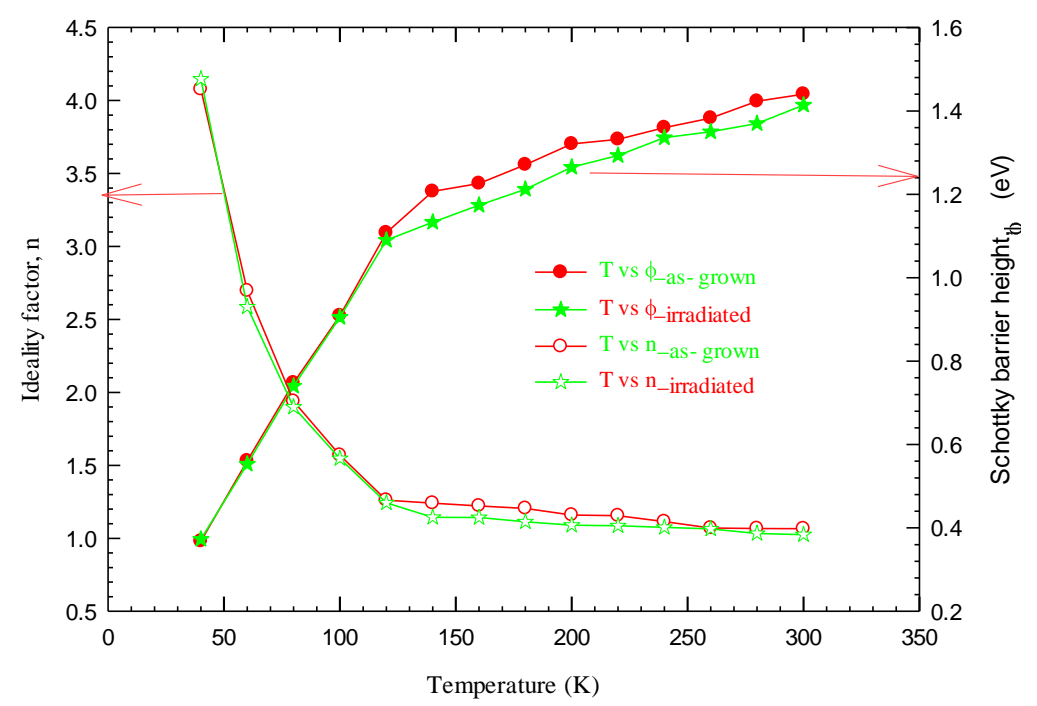

Fig. 4. Ideality factors and Schottky barrier heights as function of temperature before and after irradiation, measured at temperatures range $40-300 \mathrm{~K}$. 
Fig. 4 shows a gradual change in the ideality factor and the SBH before and after irradiation for SBD from temperature above $120 \mathrm{~K}$. It can also be deduced from the plot that there is sporadic deviation of electrical behaviours of SBD from thermionic emission theory at lower temperature (below $120 \mathrm{~K}$ ). The ideality factor and the $\mathrm{SBH}$ of the $\mathrm{Ni} / 4 \mathrm{H}-\mathrm{SiC}$ have strong reciprocal temperature dependence at lower temperatures. There was no noticeable change in the ideality factors and SBH at temperature $120 \mathrm{~K}$ and above, for before and after irradiation.

\subsection{The Richardson and the Modified Richardson plots}

The Richardson's plots of $\ln \left(I_{S} / T^{2}\right)$ as a function of $1 / T$ are shown in Figs. 5 and 6 for SBD before and after irradiation. We can re-write Eq. 1 as shown below;

$$
\ln \left(I_{S} / T^{2}\right)=\ln A A^{*}-q / k \phi_{B O} \cdot 1 / T
$$

The linear part of temperature range 120-300 K of the plots show in the graph. The Richardson constants before and after irradiation were estimated from the intercept of the plot to be $4.1 \times 10^{-8}$ and $1.2 \times 10^{-11} \mathrm{Acm}^{-2} \mathrm{~K}^{-2}$, respectively. The values are extremely small compared to the theoretical value of effective Richardson constant of $146 \mathrm{Acm}^{-2} \mathrm{~K}^{-2}[18,19]$, which indicate that the active area is smaller than the device area. The mean barrier heights for both were deduced from the slope of the plot to be 1.63 and $0.72 \mathrm{eV}$. It has been reported earlier by many researchers that the deviation of the Richardson constants from theoretical value may be as result of effect of the barrier inhomogeneity at the metal-semiconductor (MS) interface and some other factors such as crystal defects, potential fluctuation, etc [20]. Since the deviation cannot be explained by thermionic emission diffusion model, the Gaussian distribution model of barrier height can be used.

The Gaussian distribution model has been used to correct the deviation that cannot be explained with thermionic emission diffusion which occurred as a result of barrier height inhomogeneities. The deviation between experimental and theoretical values of the Richardson constants was described by the modified Richardson plot according to the aforementioned model.

Eq. 7 is obtained by combining Eq. 2 with Eq. 6.

$$
\ln \left(\frac{I_{s}}{T^{2}}\right)-\left(\frac{q^{2} \sigma^{2}}{2 k^{2} T^{2}}\right)=\ln \left(A A^{* *}\right)-\frac{q \phi_{B m}}{k T}
$$

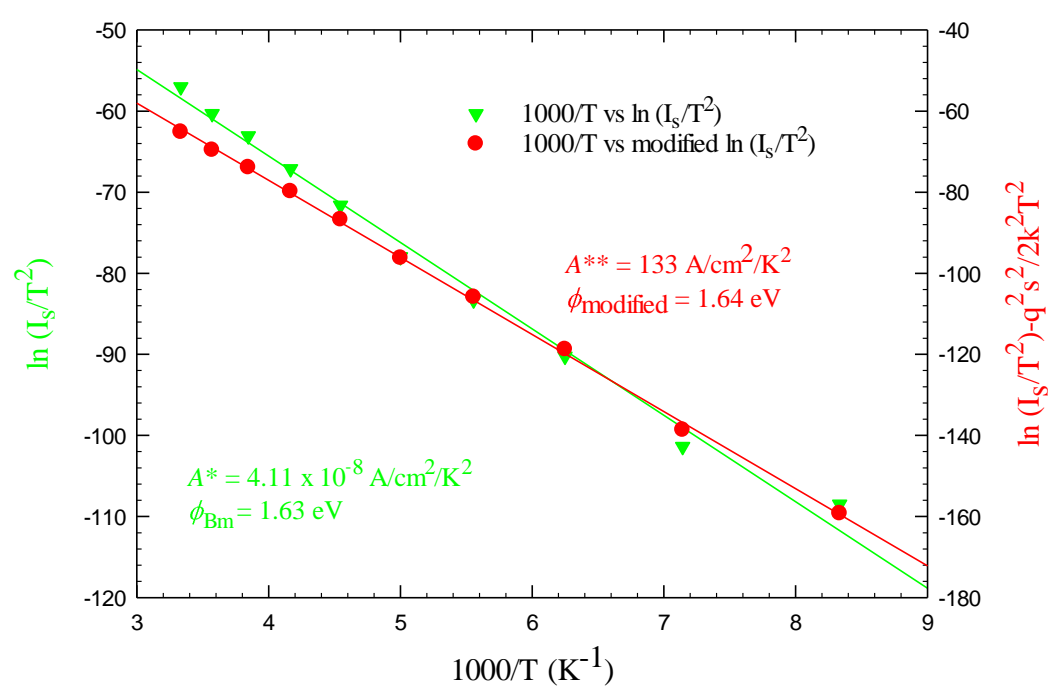

Fig. 5. The Richardson plot and the modified Richardson for as-grown Ni/4H-SiC. 


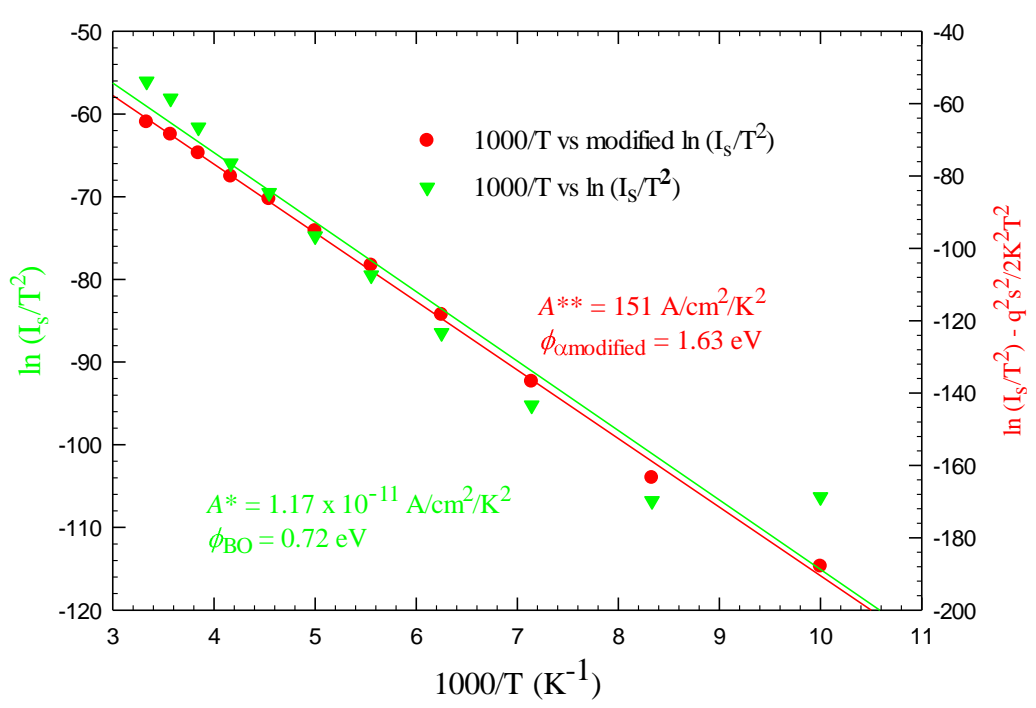

Fig. 6. The Richardson plot and the modified Richardson for Ni/4H-SiC after 2 hours irradiation.

The standard deviation, $\sigma$, (which its square was calculated to be $1.08 \times 10^{-2}$ and $1.21 \times 10^{-2}$ for as-grown and after irradiation) plays major role in estimating the modified Richardson constant, $A^{* *}$. Figs. 5 and 6 show the plot of $\ln \left(I_{s} / T^{2}\right)-\left(q^{2} \sigma^{2} / 2 k^{2} T^{2}\right)$ as function of $1000 / T$. The $A^{* *}$ before and after irradiation were determined from the intercept of the straight line to be 133 and $151 \mathrm{Acm}^{-}$ ${ }^{2} \mathrm{~K}^{-2}$, respectively. The values were in good agreement with the theoretical value. The mean barrier height before and after irradiation were estimated from the slope of the straight line as 1.64 and 1.63 $\mathrm{eV}$, respectively. There was no significant change in the value of barrier height after irradiation.

\subsection{DLTS analysis}

Fig. 7 shows the DLTS spectra for the samples before and after alpha-particle irradiation. The measurements were obtained at temperatures range $22-350 \mathrm{~K}$, at a quiescent reverse bias of $-5.0 \mathrm{~V}$, filling pulse of $1.0 \mathrm{~V}$, filling pulse width of $1.0 \mathrm{~ms}$ and a rate window of $200 \mathrm{~s}^{-1}$. Fig. 8 shows the Arrhenius plots of each defect. The signatures of the defects in term of activation energies, $E_{n}$ and apparent capture cross sections, $\sigma_{n}$ were determined from Fig. 8. The activation energy of each defect was determined from the slope, and the corresponding apparent capture cross section was calculated from the intercept of the Arrhenius plot of $\log \left(T^{2} / e_{n}\right)$ versus $1 / T$ as earlier reported by Auret et al [21]. The sample revealed the presence of four defects before irradiation, and five defects after alphaparticle irradiation as shown in Table 2. Defects with energy levels labelled as $\mathrm{E}_{0.09}, \mathrm{E}_{0.11}, \mathrm{E}_{0.16}$ and $\mathrm{E}_{0.65}$ were obtained before irradiation, and $\mathrm{E}_{0.06}, \mathrm{E}_{0.11}, \mathrm{E}_{0.15}, \mathrm{E}_{0.62}$ and $\mathrm{E}_{0.67}$ after irradiation, where ' $\mathrm{E}$ ' refers to an electron trap and the subscript 0.09 refers to an energy level below the conduction band. The properties and attributes of each defect were tabulated in Table 2. The $\mathrm{E}_{0.09}$ has been attributed to nitrogen impurities that occupy cubic site and occupy hexagonal site when the activation enthalpy is approximately $0.06 \mathrm{eV}[22,23]$. The defects $\mathrm{E}_{0.11}$ and $\mathrm{E}_{0.16}$ are related to transitional metal (titanium) $[24,25]$. The $\mathrm{E}_{0.11}$ and $\mathrm{E}_{0.16 / 0.15}$ have been reported earlier that the two levels could be a single defect occupying different geometric positions in material [26]. The $\mathrm{E}_{0.62}$ was the only defect introduced by alpha-particle irradiation, and was attributed to $Z_{1} / Z_{2} \cdot[22,27]$. It has been previously reported that $\mathrm{E}_{0.67 / 0.65}$ could be a defect complex composed of several energy levels $[28,29]$. The dominant of these energy levels is $Z_{1} / Z_{2}$ and is possibly a di-carbon or silicon interstitial next to a nitrogen atom or a hydrogen related intrinsic defect [23]. There was a shift in temperature of $E_{0.67}$ from $332 \mathrm{~K}$ to $326 \mathrm{~K}$. This was as a result of $E_{0.62}$ defect emanated after irradiation. The peak height of $E_{0.67}$ increases after irradiation as well. The formation of a new defect and the increase in intensity of some of the defects causes changes in $I-V$ and $C-V$ characteristics and the parameters of the Schottky contacts. 


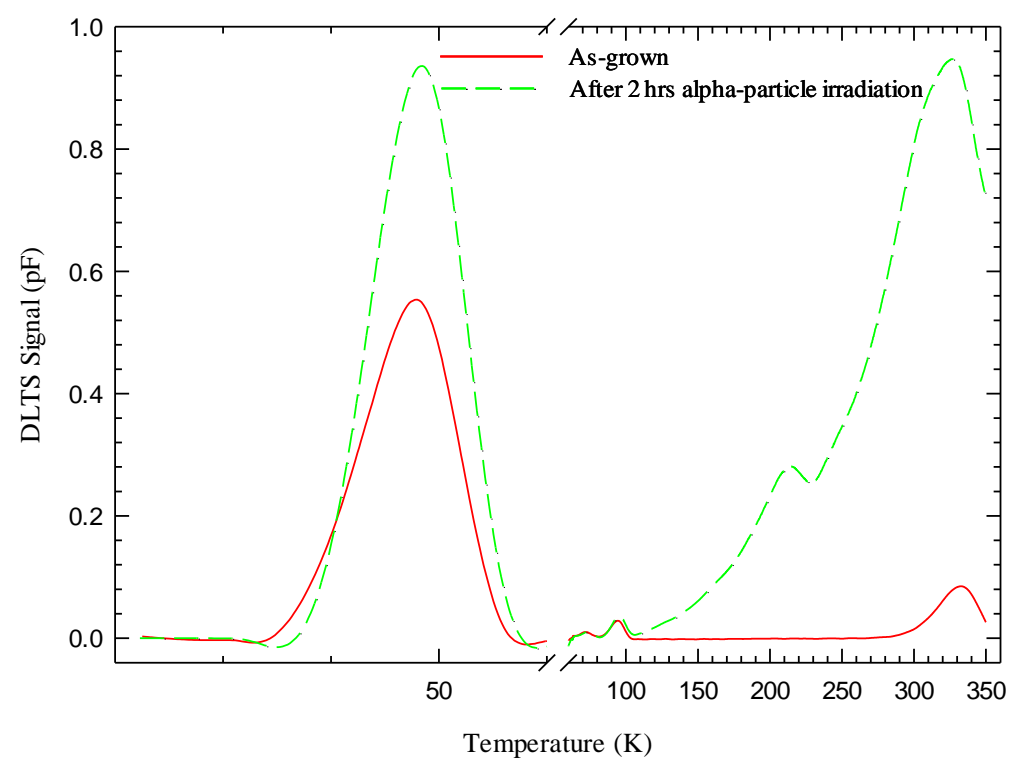

Fig. 7. DLTS spectra for the $\mathrm{Ni} / 4 \mathrm{H}-\mathrm{SiC}$ before and after alpha-particles irradiation. The temperature range $60-350 \mathrm{~K}$ scaled up to 10

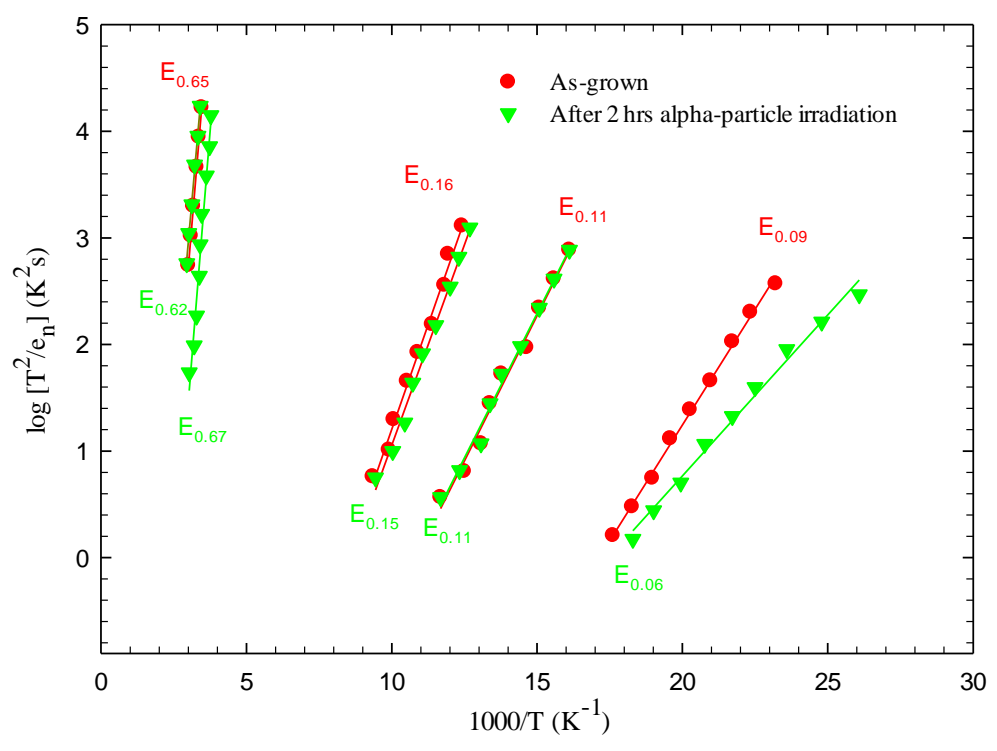

Fig. 8. The Arrhenius plots for the DLTS of as-grown and after irradiation Ni/4H-SiC.

Table 2

Electronic properties of defects detected by DLTS in as-deposited and $5.4 \mathrm{MeV}$ alpha-particles irradiation of Ni/4H-SiC.

\begin{tabular}{|c|c|c|c|c|c|c|c|c|}
\hline \multicolumn{4}{|c|}{ As-grown } & \multicolumn{4}{|c|}{ After alpha-particle irradiation } & \multirow[t]{2}{*}{ Attribution } \\
\hline Defect & $\mathrm{E}_{\mathrm{T}}(\mathrm{eV})$ & $\sigma_{\mathrm{a}}\left(\mathrm{cm}^{2}\right)$ & $\mathrm{T}_{\text {peak }}(\mathrm{K})$ & Defect & $\mathrm{E}_{\mathrm{T}}(\mathrm{eV})$ & $\sigma_{\mathrm{a}}\left(\mathrm{cm}^{2}\right)$ & $\mathrm{T}_{\text {peak }}(\mathrm{K})$ & \\
\hline $\mathrm{E}_{0.09}$ & $\mathrm{E}_{\mathrm{c}}-0.09$ & $8 \times 10^{-15}$ & 47 & $\mathrm{E}_{0.06}$ & $E_{c}-0.06$ & $6 \times 10^{-17}$ & 48 & $\mathrm{~N}$ impurity [22] \\
\hline $\mathrm{E}_{0.11}$ & $\mathrm{E}_{\mathrm{c}}-0.11$ & $2 \times 10^{-16}$ & 72 & $\mathrm{E}_{0.11}$ & $E_{c}-0.11$ & $2 \times 10^{-16}$ & 74 & Ti impurity [25] \\
\hline $\mathrm{E}_{0.16}$ & $\mathrm{E}_{\mathrm{c}}-0.16$ & $1 \times 10^{-15}$ & 94 & $\mathrm{E}_{0.15}$ & $E_{c}-0.15$ & $9 \times 10^{-16}$ & 95 & Ti impurity [24] \\
\hline - & - & - & - & $\mathrm{E}_{0.62}$ & $E_{c}-0.62$ & $1 \times 10^{-13}$ & 213 & $\mathrm{Z}_{1} / \mathrm{Z}_{2}[22,27]$ \\
\hline $\mathrm{E}_{0.65}$ & $E_{c}-0.65$ & $4 \times 10^{-15}$ & 332 & $\mathrm{E}_{0.67}$ & $E_{c}-0.67$ & $8 \times 10^{-15}$ & 326 & $\begin{array}{c}\mathrm{Z}_{1} / \mathrm{Z}_{2}(\mathrm{C} / \mathrm{Si} \\
\text { vacancy }[24,29]\end{array}$ \\
\hline
\end{tabular}

NOTE: The $\mathrm{T}_{\text {peak }}(\mathrm{K})$ was taken at rate window of $200 \mathrm{~s}^{-1}$ 


\section{Conclusions}

In conclusion, the $\mathrm{Ni} / 4 \mathrm{H}-\mathrm{SiC}$ Schottky contacts have been successfully fabricated by resistive evaporation technique. The effects of $5.4 \mathrm{MeV}$ alpha-particles irradiation measured at different temperatures on $\mathrm{Ni} / 4 \mathrm{H}-\mathrm{SiC} \mathrm{SBD}$ have been investigated using $I-V, C-V$ and conventional DLTS. The $I-V$ and $C-V$ measurements at $300 \mathrm{~K}$ before and after fluence of $5.1 \times 10^{10}$ alpha-particles- $\mathrm{cm}^{-2}$ irradiation revealed good Schottky contacts. From $I-V$ measurements, $n, S B H, R_{s}$ increases with irradiation but $I_{s}$ decreases with irradiation measured at $300 \mathrm{~K}$. $C-V$ measurements reveal decreases in free carrier concentration. The $I-V$ measurements were also repeated at temperature range $40-300 \mathrm{~K}$. The electrical behaviour of SBD deviated from thermionic emission theory at temperatures below 120 $\mathrm{K}$. The modified Richardson constants before and after alpha-particle irradiation are 133 and 151 $\mathrm{Acm}^{-2} \mathrm{~K}^{-2}$, respectively, by using Gaussian distribution method. The values of $\mathrm{A}^{* *}$ were in good agreement with the theoretical value. The electrical properties of $\mathrm{Ni} / 4 \mathrm{H}-\mathrm{SiC}$ SBDs show little response to $5.4 \mathrm{MeV}$ alpha-particle irradiation with free carrier removal rate of $7.8 \times 10^{3} \mathrm{~cm}^{-1}$ which corroborate its uses in radiation harsh environments.

\section{Acknowledgement}

This work is based on the research supported in part by the National Research Foundation (NRF) of South African (Grant specific unique reference number (UID) 78838). The Grant holder acknowledges that opinions, findings and conclusions or recommendations expressed in this publication generated by the NRF supported are that of authors and that NRF accepts no liability whatsoever in this regard.

\section{References}

[1] L.M. Tolbert, B. Ozpineci, S.K. Islam, M.S. Chinthavali, Power and Energy Systems, Proceedings, 1 (2003) 317-321.

[2] V. Kazukauskas, J.-V. Vaitkus, Opto-Electronic Review, 12 (2004) 377-382.

[3] J. Grant, W. Cunningham, A. Blue, V. O'Shea, J. Vaitkus, E. Gaubas, M. Rahman, Nuclear Instruments and Methods in Physics Research Section A: Accelerators, Spectrometers, Detectors and Associated Equipment, 546 (2005) 213-217.

[4] M.C. Driver, R.H. Hopkins, C.D. Brandt, D.L. Barrett, A.A. Burk, R.C. Clarke, G.W. Eldridge, H.M. Hobgood, J.P. McHugh, P.G. McMullin, R.R. Siergiej, S. Sriram, Gallium Arsenide Integrated Circuit (GaAs IC) Symposium, 1993. Technical Digest 1993., 15th Annual, 1993, pp. 19-21.

[5] A. Akbay, H. Korkut, K. Ejderha, T. Korkut, A. Türüt, Journal of Radioanalytical and Nuclear Chemistry, 289 (2011) 145-148.

[6] K. Çınar, C. Coşkun, Ş. Aydoğan, H. Asıl, E. Gür, Nuclear Instruments and Methods in Physics Research Section B: Beam Interactions with Materials and Atoms, 268 (2010) 616-621.

[7] K. Çınar, C. Coşkun, E. Gür, Ş. Aydoğan, Nuclear Instruments and Methods in Physics Research Section B: Beam Interactions with Materials and Atoms, 267 (2009) 87-90.

[8] J. Benkovska, L. Stuchlikova, D. Buc, L. Čaplovic, physica status solidi (a), 209 (2012) 1384 1389.

[9] T. Marinova, A. Kakanakova-Georgieva, V. Krastev, R. Kakanakov, M. Neshev, L. Kassamakova, O. Noblanc, C. Arnodo, S. Cassette, C. Brylinski, B. Pecz, G. Radnoczi, G. Vincze, Materials Science and Engineering: B, 46 (1997) 223-226.

[10] S.M. Sze, K.K. Ng, Physics of semiconductor devices, John Wiley \& Sons, 2006.

[11] E. Rhoderick, R. Williams, Oxford Science, Oxford, 1988.

[12] S. Ashok, J.M. Borrego, R.J. Gutmann, Journal of Applied Physics, 51 (1980) 1076-1084.

[13] F. Roccaforte, S. Libertino, F. Giannazzo, C. Bongiorno, F. La Via, V. Raineri, Journal of Applied Physics, 97 (2005) -.

[14] F. Auret, S. Goodman, M. Hayes, M. Legodi, H. Van Laarhoven, D.C. Look, Applied Physics Letters, 79 (2001) 3074-3076.

[15] E. Hökelek, G.Y. Robinson, Applied Physics Letters, 40 (1982) 426-428.

[16] C.R. Crowell, V.L. Rideout, Solid-State Electronics, 12 (1969) 89-105.

[17] C.R. Crowell, Solid-State Electronics, 20 (1977) 171-175. 
[18] A. Itoh, T. Kimoto, H. Matsunami, Electron Device Letters, IEEE, 16 (1995) 280-282.

[19] F. Roccaforte, F. La Via, A. Baeri, V. Raineri, L. Calcagno, F. Mangano, Journal of Applied Physics, 96 (2004) 4313-4318.

[20] İ. Dökme, Ş. Altindal, M.M. Bülbül, Applied Surface Science, 252 (2006) 7749-7754.

[21] F.D. Auret, P.N.K. Deenapanray, Critical Reviews in Solid State and Materials Sciences, 29 (2004) 1-44.

[22] T. Kimoto, A. Itoh, H. Matsunami, S. Sridhara, L. Clemen, R. Devaty, W. Choyke, T. Dalibor, C. Peppermüller, G. Pensl, Applied physics letters, 67 (1995) 2833-2835.

[23] A. Castaldini, A. Cavallini, L. Rigutti, F. Nava, S. Ferrero, F. Giorgis, Journal of Applied Physics, 98 (2005) 053706.

[24] T. Dalibor, G. Pensl, H. Matsunami, T. Kimoto, W.J. Choyke, A. Schöner, N. Nordell, physica status solidi (a), 162 (1997) 199-225.

[25] A.A. Lebedev, Semiconductors, 33 (1999) 107-130.

[26] N. Achtziger, W. Witthuhn, Applied physics letters, 71 (1997) 110-112.

[27] G. Pensl, W.J. Choyke, Physica B: Condensed Matter, 185 (1993) 264-283.

[28] T.A.G. Eberlein, R. Jones, P.R. Briddon, Physical Review Letters, 90 (2003) 225502.

[29] I. Pintilie, L. Pintilie, K. Irmscher, B. Thomas, Applied Physics Letters, 81 (2002) 4841-4843. 